\title{
EVALUATION OF CIRCULATING CATHODIC ANTIGEN (CCA) STRIP FOR DIAGNOSIS OF URINARY SCHISTOSOMIASIS IN HASSOBA SCHOOL CHILDREN, AFAR, ETHIOPIA
}

\author{
AYELE B.*, ERKO B.**, LEGESSE M.**, HAILU A.*** \& MEDHIN G.**
}

\section{Summary:}

A total of 206 urine samples collected from Hassoba Elementary schoolchildren, Afar, Ethiopia, a low Schistosoma haematobium endemic setting, was diagnosed to evaluate the performance of CCA strip using double references, urine filtration technique and urinalysis dipstick (Combur 10 Test ${ }^{\circledR}$ ) that detect schistosome eggs and blood in urine, respectively. The former was used as a gold standard reference method. Sensitivity, specificity, positive and negative predictive values for the CCA were $52 \%, 63.8 \%$, $56.7 \%$ and $59 \%$ respectively, with reference to urine filtration technique whereas these parameters were $50.4 \%, 62.4 \%$, $55.6 \%$ and $57.5 \%$ respectively, with reference to Combur 10 Test $^{\circledR}$. 47 S. haematobium egg-positive children were found negative by CCA strip while 38 egg-negative children were found positive by CCA strip. Moreover, among the pre-tests done in duplicate, inconsistent results were also recorded. Assays were also compared with regard to the cost of equipment and reagents, speed and simplicity of use. Though CCA strip was found to be rapid and could be performed with minimal training, it was found to be expensive (US \$ 4.95 per test) to use it for large-scale field use even if its diagnostic value would have been satisfactory. Further development and standardization of the CCA strip are required for its applicability for field use. It is also recommended that its cost per strip should be substantially cut down if it is to be used in poor schistosomiasis endemic countries.

KEY WORDS : urinary schistosomiasis, diagnosis, circulating cathodic antigen strip, Ethiopia.

MOTS CLÉS : schistosomiase urinaire, diagnostic, détection d'antigène cathodique circulant, Éthiopie.
Résumé : ÉVALUATION DE BANDELETTES DÉTECTANT L'ANTIGÈNE CATHODIQUE CIRCULANT (ACC) POUR LE DIAGNOSTIC DE LA SCHistosomiase uRinaire CHEZ Des ÉCOliers de Hassoba, Afar, ÉTHIOPIE

Un total de 206 échantillons d'urine prélevés chez des écoliers de Hassoba (Afar, Éthiopie), une région de faible prévalence de l'endémicité à Schistosoma haematobium, a été testé pour évaluer la valeur diagnostique de bandelettes détectant l'antigène cathodique circulant (ACC) par comparaison à la filtration pour rechercher des œufs et à la détection d'une hématurie ltest Combur 10). La filtration des urines a été considérée comme la méthode de référence. La sensibilité, la spécificité, les valeurs prédictives positives et négatives pour la détection antigénique étaient de $52 \%, 63,8 \%, 56,7 \%$ et de $59 \%$ par rapport à la filtration des urines; ces valeurs étaient de 50,4\%, 62,4\% $55,6 \%$ et $57,5 \%$ par rapport à la détection d'une hématurie. La détection antigénique a été négative chez 47 enfants ayant des œuts de S. haematobium dans les urines alors qu'elle a été positive chez 38 enfants sans oufs. En outre, des résultats contradictoires avaient été observés lors des pré-tests réalisés en double. Les coûts d'équipement et de réactifs additionnels, la vitesse d'exécution et la simplicité d'utilisation de ces tests ont également été analysés. Bien que l'utilisation des bandelettes soit rapide et ne nécessite qu'une formation minimale, leur coût demeure élevé 14,95 \$ par test) pour un usage à grande échelle et ce, même si leur valeur diagnostique avait été satisfaisante. Des améliorations et une standardisation de ces bandelettes sont donc nécessaires avant d'envisager leur utilisation sur le terrain. II est également recommandé de réduire leur coût pour pouvoir les utiliser dans les pays endémiques qui ont souvent de faibles revenus.

\section{INTRODUCTION}

T he conventional ways of demonstrating parasite eggs in feces and urine for diagnosis of infection by schistosomes have drawbacks in sensitivity, especially in case of light infection and a relatively time consuming nature of the methods in application for epidemiological assessment and clinical use (van Etten et al., 1994; Hamilton et al., 1998; Corachan, 2002; van Dam et al., 2004). Apart from egg detection in uri-

\footnotetext{
* Carter Center-Ethiopia, P.O. Box 13373, Addis Ababa, Ethiopia. ** Aklilu Lemma Institute of Pathobiology, and *** Faculty of Medicine, Addis Ababa University, P.O. Box 1176, Addis Ababa, Ethiopia. Correspondence: Berhanu Erko.

Tel.: + 251112763091 - Fax: +251 112755296

E-mail: berhanue@yahoo.com
}

nary schistosomiasis, detecting haematuria and proteinurea by urinalysis dipstick are being used as a suggestive sign for infection by the parasite in endemic areas (Kaiser et al., 1992; Wu \& Halim, 2000; Lengeler et al., 2002). Nevertheless, urinalysis dipstick is affected by different confounding factors such as menstruation and genitourinary infections (Poggensee et al., 2000). These drawbacks attracted researchers' attention for innovation of new approaches which are reliable, easy to perform and are not much demanding in terms of equipment as well as trained manpower (van Dam et al., 2004; van Etten et al., 1994).

Several immunological tests have been developed for schistosomiasis diagnosis though only few resist scrutiny of effectiveness, reproducibility, cross reactivity and predictive values (Rabello et al., 2002). The cum- 
bersome procedures and the demand of sophisticated laboratory equipment and trained personnel make these few advanced approaches inappropriate and expensive for epidemiological applications in endemic areas. For instance, in seroepidemiological surveys, apart from test procedures, sample collection and processing are sometimes cumbersome and require trained personnel for venopuncture and separation of serum samples under field conditions. Besides that, venopuncture is not widely accepted, especially by children and certain ethnic and religious groups (Noya et al., 2002).

For field-based diagnosis and follow-up of chemotherapy of schistosomiasis, there is urgent need for simple and reliable tests, which are applicable in endemic areas (van Lieshout et al., 1992, 2000; Chitsulo et al., 2004). To answer the question of simplicity in immunodiagnosis of schistosome infection, some tests use urine sample in which the appropriate marker, either antibody or antigen, to be detected is expressed (Ren $\mathrm{Li}$ et al., 2004).

Immunological techniques which measure circulating anodic antigen (CAA), a negatively charged proteo-glycan, and circulating cathodic antigen (CCA), a polysaccharide with a cathodic migration, have been developed and are being used for research purposes (Deelder et al., 1994). The existence of these circulating antigens in urine and serum without significant variation over short period of time (Disch et al., 1997; Polman et al., 1998) and rapid clearance after successful chemotherapy inspired some researchers to develop a simple and rapid dipstick as a good alternative to other conventional methods for the diagnosis of schistosome infection based on either genus or species specific monoclonal antibodies (De Jonge et al., 1990; Van't Wout et al., 1992; Deelder et al., 1994; Kremsner et al., 1994; van Dam et al., 2004; van Etten et al., 1994), preferably to be tested in urine.

In the present study, a commercially available CCAdipstick, the schistosomiasis one-step test for the detection of Schistosoma antigen (CCA) in urine, produced for research diagnostic purposes by European Veterinary Laboratory (EVL), Woerden, Holand, was evaluated under field conditions for diagnosis of urinary schistosomiasis in Hassoba village, urinary schistosomiasis endemic area in Ethiopia.

\section{MATERIALS AND METHODS}

\section{STUDY AREA}

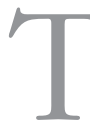
The study was conducted in Hassoba, a village in the Middle Awash Valley, Afar Region of Ethiopia. It is located about $286 \mathrm{~km}$ to the east of Addis Ababa. In the area, cotton is cultivated widely using large-scale irrigation system.
Swamps in Hassoba and its neighboring villages are known for long to be infested by Bulinus abyssincus, snail intermediate host for S. haematobium (Kloos et al., 1978; Birrie et al., 1998). The inhabitants catch schistosomiasis mainly in the swamps of the Awash River when they perform water contact activities for various reasons.

\section{SAMPLE COLLECTION}

A total of 206 urine samples were collected from schoolchildren of the Hassoba Elementary school after they had been informed and made aware of the study objectives and its benefits. As far as schistosomiasis is concerned, the area is only endemic for urinary schistosomiasis. Nevertheless, the study subjects only included those children who were born and grew up in the area and did not move anywhere since birth to exclude the probability of imported cases of schistosomiasis mansoni. Each participant was given a wide clean container to provide terminal urine between $10.00 \mathrm{a} . \mathrm{m}$. and 1.00 p.m. Each container was labeled to correspond to the code and number of the participant. Right after submission of urine sample by the participants, tests for CCA and microhaematuria were performed and $10 \mathrm{ml}$ of urine from each sample was preserved by adding $0.2 \mathrm{ml}$ of $37 \%$ formalin for egg detection by urine filtration technique later on.

\section{CCA STRIP}

A one-step, genus specific CCA strip, produced for research purpose and commercially made available by the European Veterinary Laboratory (EVL), Woerden, Holland, was evaluated for its performance in detecting gut associated antigens of adult $S$. haematobium in urine sample.

After opening the one-step pouch and placing the CCA strip test on a flat surface, a drop of fresh urine was added to the sample zone of the test, followed by addition of two drops of schistosomiasis buffer on the same zone. Within 25 minutes result was read from the test zone after comparing it to the control zone band and recorded as negative, weak positive and strong positive.

\section{URINALYSIS DIPSTICK (COMBUR $\underline{10}$ TeST $^{\circledR}$ )}

Parallel to performing CCA strip test, Combur $\underline{10}$ Test $^{\circledR}$ (Roche Diagnostics Gmbh, D-68298 Mannheim, Germany) capable of detecting urinary blood, among other nine parameters, was used to detect the presence of blood in urine as an indirect indicator of $S$. haematobium infection. After briefly dipping (about one second) the dipstick in the urine sample and leaving for a minute on a bench it was read as negative, $1+, 2+, \ldots$ $4+$ according to the manufacturer's instruction com- 
paring the test area color reaction to the matching standard labeled on the urinalysis dipstick (Combur 10 Test ${ }^{\circledR}$ ) bottle.

\section{URINE FILTRATION AND MICROSCOPY}

Within one week of collection, microscopic examination of the urine was carried out on formalin-preserved urine at the Aklilu Lemma Institute of Pathobiology (ALIPB) for detection of $S$. haematobium eggs. Urine filtration technique was used as gold standard to evaluate the performance of CCA strip. Nucleopore ${ }^{\mathrm{TM}}$ filter, a nylon mesh filter of $13 \mathrm{~mm}$ diameter and $12 \mu \mathrm{m}$ pore size (Costar Corporation, USA), was used with $10 \mathrm{ml}$ plastic syringe and its supports. The upper part of the filter support was connected to the mouth of the syringe while the bottom held the filter inside and both were tightly held together by a gasket. An extension tube was fitted to the mouth of the syringe in order to draw $10 \mathrm{ml}$ urine from the specimen after thorough mixing. The urine was forced through the filter into the filter support and the syringe was detached and was half-filled with air. The half air-filled syringe was then forced to pass through the filter in order to ensure the passage of all urine (Feldmeier et al., 1982). The filter on which the residues including $S$. haematobium eggs were found was removed with forceps and placed on a clean glass microscope slide. After adding few drops of water to the edge of the nylon mesh filters to avoid drying up, they were examined under a $10 \times$ objective lens of a binocular microscope for eggs. The number of eggs obtained per $10 \mathrm{ml}$ of urine specimen was counted using tally counter and recorded

\section{DATA ANALYSIS}

Comparison among the performances of urine filtration methods, CCA strip, and Combur 10 Test ${ }^{\circledR}$ to diagnose urinary schistosomiasis was assessed by calculating sensitivity, specificity, positive and negative predictive values. The significance of the statistical comparison among the methods was assured using $95 \%$ confidence interval and the accepted level of significance was a $P<0.05$.

\section{RESULTS}

T n this study, a total of 206 schoolchildren, 130 males and 76 females, were included. The children were in the age range of 4 to 21 years, the mean and median being 9.2 and 11, respectively. Urine filtration for microscopic detection of S. haematobium egg was used as a gold standard method to evaluate the performance of the CCA strip. Out of a total of 206 urine specimens collected from schoolchildren of Hassoba
Elementary school, 98 (47.6\%) were positive for S. haematobium eggs. Fifty-one percent of the 98 egg positive samples had egg counts of $<10$ while 14 (14.1\%) had counts of $>50$ eggs $/ 10 \mathrm{ml}$ of urine. The mean and median counts of egg were 14.8 and 0 , respectively, while the minimum and the maximum counts were 1 and 407 , respectively.

\section{URINE FILTRATION METHOD VERSUS URINALYSIS DIPSTICK (COMBUR 10 TEST ${ }^{\circledR}$ )}

As a secondary reference, urinalysis dipstick (Combur $\underline{10}$ Test) was also performed on all the 206 urine samples to evaluate the CCA strip performance. Positive results were recorded in plus system from $1+$ to $4+$ limits according to intensities of color. 89 (43.2\%) tests were positive with different level of positivity. 51 (57\%) were observed at the 4+ level, of which 14 (25.5\%) had egg count below $10 \mathrm{egg} / 10 \mathrm{ml}$ of urine and same number of cases had $>50 \mathrm{egg} / 10 \mathrm{ml}$ of urine. $38 \mathrm{egg}$ positive samples were recorded at $1+, 2+$ and $3+$ limits in aggregate. Of the total 206 samples, 78 (37.9\%) were positive by both urine filtration and urinalysis dipstick methods, whereas 97 (47.1\%) were found negative by both methods (Table I). When compared to urine filtration method, the sensitivity, specificity, positive and negative predictive values of urinalysis dipstick (Combur 10 Test ${ }^{\circledR}$ ) were calculated to be $80 \%, 91.6 \%$, $89.4 \%$ and $83.8 \%$, respectively.

\begin{tabular}{|c|c|c|}
\hline \multirow[b]{2}{*}{ Urine filtration } & \multicolumn{2}{|c|}{$\begin{array}{l}\text { Urinalysis dipstick } \\
\left(\text { Combur } \underline{10} \text { Test }^{\circledR}\right)\end{array}$} \\
\hline & Positive & Negative \\
\hline Positive & 78 & 20 \\
\hline Negative & 11 & 97 \\
\hline
\end{tabular}

Table I. - Diagnostic performance of Urinalysis dipstick (Combur $\underline{10}$ Test $^{\circledR}$ ) compared with urine filtration for the diagnosis of $S$. haematobium in Hassoba Elementary school, Afar, Ethiopia.

\section{CCA STRIP VERSUS URINE FILTRATION METHOD}

As part of quality control before the CCA strip test was applied, pre-testing was done in duplicate on samples from five children who had patent $S$. haematobium infections and from four healthy males (among the study subjects) who came from a schistosome free area. Surprisingly, one case that excreted eggs and two cases that were negative for $S$. haematobium eggs showed inconsistent results (urine sample collected at a time and tested by two strips, one showing positive while the other showing negative results). But in all positive and negative cases throughout the examination, the positive control reaction zones of the CCA strip were clearly visible, so there was no invalid test recorded. In the actual examinations of urine samples, where 
single CCA strips were used, 90 (43.2\%) out of the examined 206 urine samples were positive, of which 45 (48\%) were weak positive for S. haematobium infection.

Out of 98 egg positive cases, 47 (48\%) were negative by CCA strip test, of which 20 (42.6\%) had egg count of $>10 / 10 \mathrm{ml}$ urine. On the other hand, out of $108 \mathrm{egg}$ negative confirmed samples, 39 (36\%) were found to be positive by CCA strip. On the basis of these results, as shown in Table II, the calculated Sensitivity (SS), Specificity (SP), Positive predictive value (PPV) and Negative predictive value (NPV) were found to be $52 \%$, $63.8 \%, 56.7 \%$ and $59 \%$, respectively.

\begin{tabular}{ccc}
\hline & \multicolumn{2}{c}{ Urine filtration } \\
\cline { 2 - 3 } CCA strip & Positive & Negative \\
\hline Positive & 51 & 39 \\
Negative & 47 & 69 \\
\hline
\end{tabular}

Table II. - Diagnostic performance of CCA strip compared with urine filtration for the diagnosis of urinary schistosomiasis in Hassoba Elementary school, Afar, Ethiopia.

\section{INTENSITY OF THE INFECTION BY URINE FILTRATION AND CCA STRIP METHODS}

Among the total of 89 positive samples by CCA strip test, $44(49.4 \%)$ and 45 (50.6\%) were grouped as strong and weak positives respectively. Among the 44 strong and 45 weak positive samples, 17 (38.6\%) and 20 (44.4\%) were negative by urine filtration method respectively. Among 83 individuals who had egg counts < 50/10 ml urine, 21 (25.3\%), $20(24.1 \%)$ and $42(50.6 \%)$ were found to be strong positive, weak positive and negative respectively, by CCA strip test. Similarly, of the 15 subjects who had egg counts $>50 / 10 \mathrm{ml}$ urine, $6(40 \%), 5(33.3 \%)$ and $4(26.7 \%)$ were found to be strong positive, weak positive and negative respectively, by CCA strip test. Figure 1 depicts the association between intensity of infection by urine filtration and CCA strip methods.

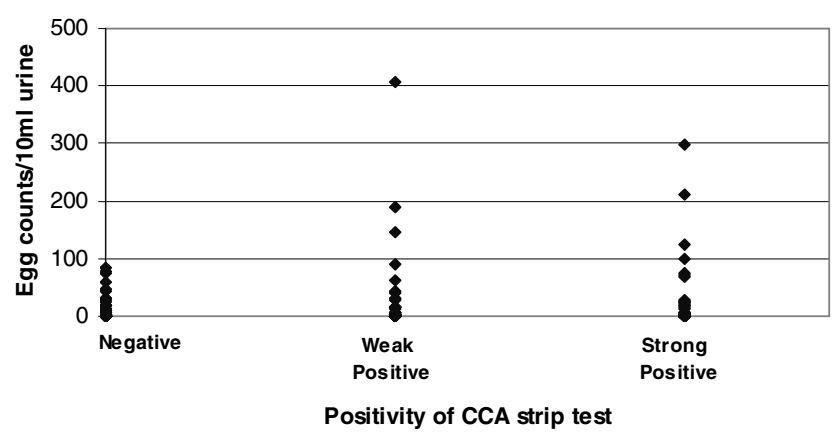

Fig. 1. - Association of CCA strip test results with infection intensity of urinary schistosomiasis expressed as egg counts per $10 \mathrm{ml}$ of urine sample.

\section{CCA STRIP VERSUS URINALYSIS DIPSTICK (Combur 10 Test $^{\circledR}$ )}

Out of 89 blood positive urine detected by urinalysis dipstick (Combur 10 Test $^{\circledR}$ ), 44 (49.4\%) were negative by CCA strip test, of which 25 were 3+ and $4+$ level and 19 were $1+$ and $2+$. Similarly, of the 90 samples found to be positive by CCA strip, 45 (50\%) samples were found to be negative by urinalysis dipstick. Sensitivity, specificity, positive and negative predictive values of CCA strip with reference to urinalysis dipstick was calculated to be $51 \%, 61.9 \%, 50 \%$ and $63 \%$, respectively (Table III).

\begin{tabular}{ccc}
\hline & \multicolumn{2}{c}{$\begin{array}{l}\text { Urinalysis dipstick } \\
\text { (Combur } \underline{\text { 10 }} \text { Test }^{\circledR} \text { ) }\end{array}$} \\
\cline { 2 - 3 } CCA strip & Positive & Negative \\
\hline Positive & 45 & 45 \\
Negative & 44 & 73 \\
\hline
\end{tabular}

Table III. - Diagnostic performance of CCA strip compared with Urinalysis dipstick (Combur $\underline{10}$ Test $^{\circledR}$ ) for the diagnosis of S. haematobium in Hassoba Elementary school, Afar, Ethiopia.

\section{COMPARISON OF URINE FILTRATION, URINALYLIS DISPTICK AND CCA STRIP TESTS}

Of the total 206 samples, 42 (20.4\%) and 63 (30.6\%) samples were positive and negative by all the three methods, respectively. Ten (4.9\%) samples were found to be positive by urine filtration, but negative by both CCA strip and dipstick tests. Only three (1.5 \%) samples which were negative by urine filtration were found to be positive both CCA strip and dipstick tests. 34 (16.5\%) samples were positive by CCA strip, but found to be negative by urine filtration and dipstick test. On the other hand, 36 (17.5\%) samples were negative by CCA strip test, but found to be positive by urine filtration and dipstick test. Eight (3.9\%) positive samples by dipstick test were found to be negative by urine filtration and CCA strip methods, while 10 (4.9\%) negative samples by dipstick were found to be positive by the two techniques.

\section{DISCUSSION}

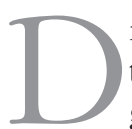
iagnosis of human schistosomiasis is very central to make a decision on individual case management, at all stages of control programs and for comparing control programs (Sturrock, 2001; Feldmeier et al., 1993). Although the most reliable way to diagnose urinary schistosomiasis is the detection of eggs in urine by filtration method, failure to recover eggs does not rule out the possibility of infection for 
a number of reasons. Hence, a diagnostic tool should be sensitive enough to detect all infected individuals irrespective of duration of infection.

In various previous studies, sensitivities for circulating antigens in general have been reported to be lying between 65 and 85 \% (De Jonge et al., 1991; van Lieshout et al., 1992; Stothard et al., 2006). Similar results were obtained in a study carried out by Legesse \& Erko (2007) in schistosomiasis mansoni endemic focus in Ethiopia. Furthermore, urine-CCA has been claimed to be useful in the diagnosis of schistosomiasis while a recent study by Stothard et al. (2006) revealed its absolute failure in detecting $S$. haematobium antigen. In studies done in Zanzibar, Niger and Burkina Faso, the CCA strip was not able at all to detect active cases of urinary schistosomiasis while it showed promising results in S. mansoni infection. The possible explanation given by Stothard et al. (2006) for the CCA strip being efficient for the diagnosis of $S$. mansoni infection but failure in urinary schistosomiasis was stated as "the stoichiometry of the antigen-antibody interaction such that the concentration of urine-CCA typically that is found in intestinal schistosomiasis must be significantly greater than that found in urinary schistosomiasis or the antibody formulation has a much greater affinity".

In the present study, we used the CCA strip similar to that of Stothard et al. (2006) that was also purchased from the same source (EVL). In our field-based study, the sensitivity and specificity of CCA strip with reference to urine filtration method, as a gold standard method, were 52 and $64.5 \%$, respectively. These findings clearly differ from those of Stothard et al. (2006) because positive results were obtained in urinary schistosomiasis but of poor performance. On the other hand, this result is lower than the result of previous study, which showed a high sensitivity of urine-CCA assay for the diagnosis of S. haematobium (De Clercq et al., 1997). Previous studies have indicated that the potential of the reagent strip test to predict the presence or absence of infection with schistosomes is dependent on the prevalence of the disease in the population tested (Stothard et al., 2006; Van Dam et al., 2004). Hence, the difference in sensitivity observed in urine-CCA assay between the present and previous studies is probably due to the difference in the level of endemicity of the disease in various study areas. Nevertheless, the sensitivity of the reagent strip test is expected to be higher than the sensitivity of the urine filtration method in areas where the prevalence of schistosomiasis is expected to be low. Thus, the present low sensitivity as well as inconsistency in the results during pre-testing on duplicate samples might indicate the need for further refinement of the antigen test used as well as the need for looking into genetic variations.
In addition to the issue of sensitivity, high specificity of a reagent strip test is also very important to reduce false positivity in endemic areas of the disease. Reagent strip test has been criticized for its low specificity in an area where schistosomiasis was not found in Ethiopia (Legesse \& Erko 2007). In the present study, the low specificity of the reagent strip test observed might be due to the low sensitivity of the gold standard test (urine filtration test). The low specificity and the detection of many samples as positive by the urine CCA assay, which were negative by both urine filtration and urinalysis dipstick methods, necessitates further studies on the specificity of this test.

In this study, evaluation of CCA strip was also made with reference to urinalysis dipstick (Combur 10 Test $^{\circledR}$ ). Though urinalysis dipstick (Combur $\underline{10}$ Test $^{\circledR}$ ) is not a gold standard reference method for urinary schistosomiasis diagnosis, it is used for epidemiological surveys where the endemicity of urinary schistosomiasis has already been established or to measure the impact of control program in endemic areas. So, on the basis of our evaluation, CCA strip showed poor performance as compared to Combur 10 Test ${ }^{\circledR}$. Moreover, a high disparity was observed between the CCA strip test and the other two methods, while low disparity was observed between dipstick and urine filtration techniques. For instance, 34 subjects who were found to be positive by CCA strip test were found negative by dipstick and urine filtration methods. Similarly, 36 subjects who were negative by CCA strip test were found to be positive by the two tests.

In the present study, most of the subjects who were negative by CCA strip test, but positive by urine filtration had egg counts $<50 / 10 \mathrm{ml}$ urine. Although the effect of day-to-day variation of egg output in urine (Van Etten et al., 1997) and individual differences in microscopic egg counts should not be overlooked, most of the subjects who were scored as strong positive by CCA strip test were among those subjects who had egg counts $<50 / 10 \mathrm{ml}$ urine. In contrast to several previous studies that indicated a positive association between urine CCA assay and parasitological method to indicate the intensity of infection with $S$. mansoni (Stothard et al., 2006; Legesse \& Erko, 2007), the result observed in this study dose not suggest the potential use of urine CCA assay as an alternative to parasitological method to assess the intensity in urinary schistosomiasis.

Besides the question of effectiveness, the cost for a single CCA strip (including packaging and shipment costs) was about US $\$ 4.95$ per strip, which is not affordable for the purpose of large scale field studies in schistosomiasis endemic areas. This is also considered as a limitation to use CCA strip in schistosomiasis endemic areas. Regarding the cost-effectiveness of the microscopy, it is obvious that all materials used for urine fil- 
tration (microscopes, filters, syringes) are re-useable for many years once they are acquired. Furthermore, microscope is not only used for the purpose of urine examination but also used for examination of other specimens. Hence, microscopy seems to be cost-effective as compared to CCA strips. So, at the present condition, tests for microhaematuria which costs approximately US \$ 0.32 per urinalysis dipstick test and urine filtration for detection of $S$. haematobium egg are the method of choice for mass screening, treatment and follow-up studies. Nevertheless, the CCA strip test is simple to perform, takes less time and it does not need sophisticated equipment and skilled manpower.

\section{CONCLUSIONS}

A ccording to the present findings, further development and standardization of the CCA strip is suggested for its applicability for the diagnosis of urinary schistosomiasis under hypo- and hyperendemic settings. Furthermore, cost per strip should also substantially be reduced if it is to be used in poor schistosomiasis endemic countries.

\section{ACKNOWLEDGEMENTS}

This study was financially supported by the Academic Vice President for Research and Graduate Programs (AVPRGPs) office of the Addis Ababa University and the Third World Academy of Sciences (TWAS). We would also like to thank schoolchildren and teachers of Hassoba Elementary School and Community leaders of the Hassoba village for their cooperation during the field work.

\section{REFERENCES}

Birrie H., Tedla S., Tilahun G., Kloos H. \& Eshete H. Schistosomiasis and its distribution in Ethiopia and Eritrea, in: Schistosomiasis in Ethiopia and Eritrea. Birrie H., Tedla S. \& Jemaneh L. (eds). Institute of Pathobiology, AAU, Printing Press, 1998, 29-86.

Chitsulo L., Loverde P. \& Engels D. Schistosomiasis. Nature Reviews Microbiology, 2004, 2 (1), 12-13.

Corachan M. Schistosomiasis and international travel. Clinical Infectious Diseases, 2002, 35, 446-450.

Deelder A.M., Qian Z.L., Kremsner P.G, Acosta L., Rabello A.L.T., Enyong P., Simarro P.P., Van Etten C.M., Krijiger F.W., Rotmans J.P., Fillie Y.E., De Jonge N., Agnew A.M. \& VAN LIESHOUT L. Quantitative diagnosis of schistosoma infection by measurement of circulating antigens in serum and urine. Tropical and Geographical Medicine, 1994, 46, 233-238.
De Clerce D., Sacko M., Vercruysse J., Vanden Bussche V., Landoure A., Diarra A., Gryseels B. \& Deelder A. Circulating anodic and cathodic antigen in serum and urine of mixed Schistosoma haematobium and S. mansoni infections in Office du Niger, Mali. Tropical Medicine \& International Health, 1997, 2 (7), 680-685.

Disch J., Garcia M.M., Krijger G.W., Amorim M.N., Katz N., Deelder A.M., Gryseels B. \& Rabello A. Daily fluctuation of levels of circulating cathodic antigen in urine of children infected with Schistosoma mansoni in Brazil. Transactions of the Royal Society of Tropical Medicine and Hygiene, 1997, 91 (2), 222-225.

De Jonge N., Kremsner P.G., Krijger F.W., Schommer G., Fillie Y.E., Kornelis D., van Zeyl R.J.M., van Dam G.J., FeldMeIER H. \& DeELDER A.M. Detection of the schistosome circulating cathodic antigen by enzyme immunoassay using biotinylated monoclonal antibodies. Transactions of the Royal Society of Tropical Medicine and Hygiene, 1990, 84, 815-818.

De Jonge N., Rabello A., Krijger F.W., Kremsner P.G., Rocha R.S., Katz N. \& Deelder A.M. Levels of the schistosoms circulating anodic and cathodic antigens in serum of schistosomiasis patients from Brazil. Transactions of the Royal Society of Tropical Medicine and Hygiene, 1991, 85, 756759 .

Feldmeier H., Doehring E. \& Daffalla A.A. Simultaneous use of sensitive filtration technique and reagent strips in urinary schistosomiasis. Transactions of the Royal Society of Tropical Medicine and Hygiene, 1982, 7, 1005-1007.

Feldmeier H. Diagnosis, in: Human schistosomiasis. Jordan P., Webbe G. \& Sturrock R.F. (eds). CAB International, Wallingford, 1993, 271-303.

HAmilton J.V., KuInKerT M. \& DOEnhoff M.J. Diagnosis of schistosomiasis: antibody detection, with notes on parasitological and antigen detection methods. Parasitology, 1998, $117,41-45$.

Kaiser C., Bergel F., Schwerdtfeger E.D., Feldmeier H. \& EHRICH J.H.H. Urine test strips: reliability of semi-quantitative findings under tropical conditions. Pediatrics Nephro$\log$, 1992, 6, 145-148.

Kloos H., Lemma A. \& De Sole G. Schistosoma mansoni distribution in Ethiopia: a study in medical geography. Annals of Tropical Medicine and Paristology, 1978, 72, 461-470.

Kremsner P.G., Enyong P., Krijger F.W., De Jonge N., Zotter G.M., Thalhammer F., Muhlschleagel F., Bienzle U., FeldMeIer H. \& DeElder A.M. Circulating anodic and cathodic antigen in serum and urine from Schistosoma haematobium infected Cameronian children receiving prazequantel. Clinicl Infectious Diseases, 1994, 18, 405-413.

LEGESSE M. \& ERKO B. Field-based evaluation of a reagent strip test for diagnosis of Schistosoma mansoni by detecting circulating cathodic antigen in urine before and after chemotherapy. Transactions of the Royal Society of Tropical Medicine and Hygiene, 2007, 101, 668-673.

Lengeler C., Utzinger J. \& TANNER M. Questionnaires for rapid screening of schistosomiasis in sub-Saharan Africa. Bulletin of World Health Organization, 2002, 80, 1-19.

Poggensee G., Krantz I., Kiwelu I. \& Feldmeier H. Screening of Tanzanian women of childbearing age for urinary schis- 
tosomiasis: validity of urine reagent strip readings and selfreported symptoms. Bulletin of World Health Organization, 2000, 78 (4), 542-548.

Polman K, Engels D, Fathers L, Deelder A.M. \& Gryseels B. Day-to-day fluctuation of schistosome circulating antigen levels in serum and urine of humans infected with Schistosoma mansoni in Burundi. American Journal of Tropical Medicine and Hygiene, 1998, 59 (1), 150-154.

Noya O., Alarcun de Noya B., Losada S., Colmenares C., Guzm N.C. \& Lorenzo M.A. Laboratory diagnosis of schistosomiasis in areas of low transmission. Memorias Do Instituto Oswaldo Cruz, 2002, 97, 167-169.

Rabello A., Pontes L.A. \& Dias-Neto A. Recent advances in the diagnosis of schistosoma infection: the detection of parasite DNA. Memorias Do Instituto Oswaldo Cruz, 2002, 97, 171-172.

Ren Li Z., Lian Hua, H., Ping Fang W. et al. Detection of IgG antibody and subclass from urine patients infected with Schistosoma japonicum. China Tropical Medicine, 2004, 4 (2), 156-158.

Stothard J.R., Kabatereine N.B., Tukahebwa E.M., Kazibwe F., Rollinson D., Mathieson W., Webster J.P. \& Fenwick A. Use of circulating cathodic antigen (CCA) dipsticks for detection of intestinal and urinary schistosomiasis. Acta Tropica, 2006, 97, 219-228.

STURROCK R.F. Schistosomiasis epidemiology and control: how did we get here and where should we go? Memorias Do Instituto Oswaldo Cruz, 2001, 96 (suppl.), 17-27.

van Dam G.J., Wichers J.H., Falcao Ferreira T.M., Ghati D., van Amerongen A. \& Deelder A.M. Diagnosis of schistosomiasis by reagent strip test for detection of circulation cathodic antigen. Journal of Clinical Microbiology, 2004, 42, 5458-5461.

van Etten L., Folman C.C., Eggelte T.A., Kremsner P.G. \& DEELDER A.M. Rapid diagnosis of schistosomiasis by antigen detection in urine with a reagent strip. Journal of Clinical Microbiology, 1994, 32, 2404-2406.

van Etten L., Kremsner P.G., Krijger F.W. \& Deelder A.M. Day-to-day variation of egg output and schistosome circulating antigens in urine of Schistosoma heamatobium infected school children from Gabon and follow-up after chemotherapy. American Journal of Tropical Medicine and Hygiene, 1997, 57 (3), 337-341.

van Lieshout L., De Jonge N., el Masry N. A., Mansour M.M., KRIJger F.W. \& DeElder A.M. Improved diagnostic performance of the circulating antigen assay in human schistosomiasis by parallel testing for circulating anodic and cathodic antigens in serum and urine. American Journal of Tropical Medicine and Hygiene, 1992, 47, 463-469.

van Lieshout L., De Jonge N., Mansour M.M., Bassily S., KrijGER F.W. \& DEELDER A.M. Circulating cathodic antigens levels in serum and urine of schistosomiasis patients before and after chemotherapy with praziquantel. Transactions of the Royal Society of Tropical Medicine and Hygiene, 1993, 87, 311- 312.

Van't Wout A.B., De Jonge N., Tiu Wu, Garicia E.E., MitCHELl G.F. \& DeELDER A.M. Schistosome circulating anodic antigen in serum of individuals infected with Schistosoma japonicum from the Philippines before and after chemo- therapy with praziquantel. Transactions of the Royal Society of Tropical Medicine and Hygiene, 1992, 86, 410-413.

van Lieshout L., Polderman A.M. \& DeElder A.M. Immunodiagnosis of schistosomiasis by determination of the circulating antigens CAA and CCA, in particular in individuals with recent or light infections. Acta Tropica, 2000, 77 (1), 69-80.

Wu Gy \& Halim M.H. Schistosomiasis: Progress and Problems. World Journal of Gastroenterology, 2002, 6, 12-19.

Reçu le 12 mars 2007 Accepté le 6 novembre 2007 